\title{
Analisis Hasil Pendukung Keputusan Mendapatkan Rumah Dinas Perusahaan Menggunakan Metode Analytical Hierarchy Process (AHP) dan Technique for Order Preference by Similarity to Ideal Solution (TOPSIS)
}

\author{
Andi Zulherry, T S Gunawan, Wanayumini* \\ Fakultas Teknik dan Ilmu komputer, Prodi Magister Ilmu Komputer, Universitas Potensi Utama, Medan, Indonesia \\ Email: ${ }^{1}$ andi.zulherry@gmail.com, ${ }^{2}$ tsgunawan@gmail.com, ${ }^{3,}{ }^{*}$ wanayumini@gmail.com \\ Email Penulis Korespondensi: wanayumini@gmail.com
}

\begin{abstract}
Abstrak-Perusahaan Bridgestone adalah perusahaan yang bergerak dalam bidang perkebunan, pada saat ini memiliki karyawan berjumlah 230 Staff/karyawan, setiap karyawan berhak mendapatkan rumah dinas, ini menuntut perusahan untuk melakukan analisa keputusan untuk menentukan rumah dinas kepada setiap karyawan yang akan mengajukan permohonan fasilitas rumah dinas tersebut. untuk mengurangi tingkat ketidak transparan dan keakuratan data yang bisa menimbulkan gejolak dan kesenjangan terhadap setiap karyawan. Maka dilakukan analisis Hasil Pendukung Keputusan Mendapatkan Rumah Dinas Perusahaan Menggunakan Metode Analytical Hierarchy Process (Ahp) Dan Technique For Order Preference By Similarity To Ideal Solution (TOPSIS). Pada hasil akhir evaluasi uji coba metode AHP menghasilkan data akurat dimana terdapat 5 orang karyawan yang benar-benar masuk kategori sangat layak untuk mendapatkan rumah dinas. Sedangkan pada metode AHP terdapat perbedaan hasil yang di temukan, dimana ditemukan karyawan berjumlah 1 orang yang harusnya dalam kategori layak tetapi masuk ke katogori sangat layak, sehingga jumlah yang di hasilkan dari metode TOPSIS berjumlah 6 orang. Dengan adanya 2 metode tersebut dapat menghasilkan nilai akurasi sekita 60\% dengan memasukkan semua criteria - kriteria yang ditentukan.
\end{abstract}

Kata Kunci: Cosine Similarity; Text Mining; Pembobotan; Machine Learning

\begin{abstract}
The Bridgestone company is a company engaged in the plantation sector, currently it has employees of 230 staff/employees, every employee is entitled to an official residence, This requires the company to conduct a decision analysis to determine the official residence for each employee who will apply for the official housing facility. to reduce the level of lack of transparency and accuracy of data that can cause turmoil and gaps for each employee. Then an analysis of the results of decision support for obtaining a company official residence was carried out using the Analytical Hierarchy Process (Ahp) and Technique For Order Preference By Similarity To Ideal Solution (TOPSIS). The final results of the AHP method trial evaluation result in accurate data where there are 5 employees who are truly in the very feasible category to get an official residence. Whereas in the AHP method there are differences in the results found, where it is found that the number of employees is 1 person who should be in the feasible category but belongs to the very feasible category, so that the number generated from the TOPSIS method is 6 people. With these 2 methods, it can produce an accuracy value of around $60 \%$ by entering all the specified criteria.
\end{abstract}

Keywords: Similarity; Text Mining; Weighted; Machine Learning

\section{PENDAHULUAN}

Salah satu perusahaan di Indonesia, yang memiliki kompleks perumahan atau rumah dinas yang dibangun untuk kesejahteraan dan kenyamanan pekerja. Kompleks perumahan yang dibangun di lingkungan perkebunan dengan berbagai tipe ditambah taman terbuka hijau, masjid dan fasilitas umum lainnya juga berwawasan lingkungan.

Salah satu permasalahan yang ada pada perusahaan tersebut yaitu masih mengalami kesulitan dalam hal penentuan pemberian rumah dinas kepada pekerja dikarenakan masih bersifat subjektif, karena proses penilaian menggunakan hanya satu kriteria saja yang membuat pekerja tersebut langsung mendapatkan rumah dinas. Tetapi dalam beberapa kriteria - kriteria yang lain pekerja tersebut belum tentu unggul, namun tetap mendapatkan rumah dinas. Hal ini ditakutkan menimbulkan suatu ketidakadilan dalam pemilihan pekerja yang berhak mendapatkan rumah dinas, hal ini di sebabkan tidak adanya sistem yang dapat memberikan alternatif solusi dalam proses pemilihan pekerja untuk mendapatkan rumah dinas. Karyawan yang seharusnya mendapatkan penilaian kinerja terbaik justru tidak memperoleh rumah dinas yang menjadi haknya. Pihak manajemen belum bisa membuat suatu analisa yang efektif, mengingat belum adanya sistem untuk proses penilaian terhadap karyawan. Untuk itu diperlukan sebuah sistem yang dapat memberikan hasil perangkingan dalam penilaian kinerja karyawan yang berupa nilai yang di dapat digunakan untuk mengetahui penilaian karyawan terbaik untuk mendapatkan rumah dinas.

Metode AHP (Analytical Hierarchy Process) merupakan sebuah hirarki fungsional dengan input utamanya persepsi manusia. Dengan hirarki, suatu masalah kompleks dan tidak tersruktur dipecahkan kedalam kelompok kelompoknya, kemudian kelompok-kelompok tersebut diatur menjadi suatu bentuk hirarki. Sedangkan metode TOPSIS (Technique For Order Preference by Similarity to Ideal Solution) dalam melakukan perankingan untuk menentukan alternatif terpilih dengan menggunakan input bobot kriteria.

Metode AHP (Analytical Hierarchy Process) bekerja sebagai pembobotan kriteria dan uji tingkat konsistensi terhadap matriks perbandingan berpasangan [1]. Jika matriks telah konsisten maka dapat dilanjutkan 
ke proses metode TOPSIS (Technique For Order Preference by Similarity to Ideal Solution) dalam melakukan perankingan untuk menentukan alternatif terpilih dengan menggunakan input bobot kriteria yang diperoleh dari metode AHP [2].

Pada artikel penelitian, metode Fuzzy-TOPSIS dapat digunakan sebagai pilihan untuk menyelesaikan permasalahan ketidakpastian penentu keputusan. Proses untuk menentukan kelayakan dalam memilih rumah dinilai lebih efektif bila dibandingkan dengan cara manual. Penelitian ini bertujuan merancang sebuah Sistem Pendukung Keputusan Penentuan rumah sehat dan rumah tidak sehat yang dapat membantu petugas kesehatan/masyarakat dalam memilih rumah sehat dan tidak sehat yang tepat dengan menggunakan Microsoft excel. Dari hasil perhitungan metode TOPSIS dapat menjadi masukan bagi dinas kesehatan terkait untuk menindaklanjuti prioritas rumah tidak sehat. Hasil penelitian ini yaitu system pendukung keputusan kelayakan bantuan rumah tidak layak huni (RTLH) dengan menggunakan metode TOPSIS yang dibangun sebagai alat bantu dalam menentukan kelayakan bantuan RTLH [3]. Sedangkan pada penelitian Untuk mengekspresikan preferensi pengambil keputusan pada alternatif yang paling diinginkan, dapat dilakukan dengan menerapkan Technique for Order Preference by Similarity to Ideal Solution (TOPSIS). Metode TOPSIS akan di kombinasikan dengan logika fuzzy untuk menentukan nilai bobot pada setiap atribut kriteria, yang dilanjutkan dengan proses perangkingan untuk menyeleksi alternatif terbaik, dalam hal ini adalah alternatif yang valid sebagai penerima bantuan yang sesuai dengan kriteria [4]. Dengan metode ini diharapkan proses penilaian akan lebih tepat dan akurat karena didasarkan pada nilai kriteria dan bobot yang telah ditentukan.

Tujuan penelitian ini adalah analisa hasil menggunakan metode Analytical Hierarchy Process dan Technique for Order Preference by Similarity to Ideal Solution (AHP dan TOPSIS) pemberian rumah dinas terhadap karyawan pada perusahaan Bridgestone sumatera utara.

\subsection{Tahapan Penelitian}

\section{METODOLOGI PENELITIAN}

Penelitian ini dilakukan di perusahaan Bridgestone, yang merupakan salah satu perusahaan yang berada di Provinsi Sumatera Utara. Penelitian dilakukan agar hasil penelitian dapat digunakan sebagai solusi dan pengembangan terhadap perusahaan dalam pengelolaan penentuan rumah dinas terhadap karyawan. Berdasarkan tipe penelitian, data yang digunakan dalam penelitian ini adalah:

1. Data kuantitatif adalah data yang hampir semuanya mencakup data numerik.

2. Data Kualitatif adalah data yang berbentuk kata, kalimat, gerak tubuh, ekspresi wajah, bagan, gambar, dan foto. Data kualitatif ini digunakan sebagai pelengkap, memperjelas dan memperkuat data kuantitatif dalam menganalisis data yang diteliti.

Adapun jenis data yang digunakan dalam penelitian ini adalah data primer dan data sekunder.

1. Data Primer

Data primer dalam penelitian ini diperoleh secara langsung dari objek penelitian. Data primer yang dikumpulkan adalah data yang diperoleh dari prusahaan secara langsung dengan mengajukan permintaan data yang diperlukan oleh peneliti kepada prusahaan Bridgestone terkait data karyawan yang sedang melakukan pengajuan untuk mendapatkan rumah dinas.

\section{Data Sekunder}

Data sekunder merupakan suatu data yang diperoleh secara tidak langsung melalui studi kepustakaan yaitu dengan membaca kepustakaan seperti buku-buku literatur, diktat-diktat kuliah, majalah, jurnal, buku yang berhubungan dengan pokok penelitian, surat kabar dan membaca dan mempelajari arsip-arsip atau dokumen-dokumen yang terdapat di instansi-instansi yang terkait. Untuk melengkapi paparan hasil penelitian juga digunakan rujukan dan referensi dari bank data lain yang relevan, misalnya jurnal, laporan hasil penelitian terdahulu, serta publikasi yang relevan dengan penelitian ini.

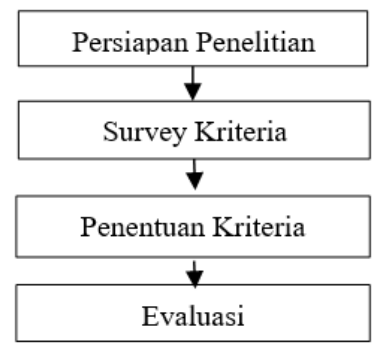

Gambar 1. Tahapan Penelitian

\subsection{Metode Analisis Data}

Data yang sudah dikumpulkan, baik primer maupun sekunder untuk selanjutnya di analisa. Metode yang digunakan untuk melakukan analisis data adalah : 
Metode AHP (Analytical Hierarchy Process) dalam Penelitian ini digunakan untuk menentukan bobot kriteria dalam penentuan rumah dinas pada prusahaan Bridgestone. Dimana keputusan diambil dengan cara membandingkan secara berpasangan alternaf yang telah dipilih dengan menggunakan kuesioner perbandingan bepasangan yang melibatkan para responden ahli yang memahami mengenai produk industri kecil. Penentuan responden ahli (expert) ditetapkan dengan cara purposive dan ditetapkan langsung berdasarkan kepentingan dan pengetahuannya. Pada dasarnya langkah-langkah dalam metode Analytical Hierarchy Process

(AHP) adalah sebagai berikut :

1. Penyusunan struktur hirarki dari permasalahan yang dihadapi Permasalahan kompleks yang akan diselesaikan, dapat dipahami dengan cara menguraikan menjadi unsur-unsur pendukung yaitu kriteria dan alternatif kemudian disusun menjadi struktur hirarki.

2. Penilaian kriteria dan alternatif

kriteria dan alternatif dilakukan dengan menilai perbandingan berpasangan. Menurut Saaty, dalam berbagai persoalan digunakan skala 1 s.d 9 adalah skala yang terbaiak dalam mengekspresikan pendapat. Berikut ini disajikan skala perbandingan berpasangan.

Langkah Analisa dari metode TOPSIS mengikuti langkah berikut ini:

1. Matriks Keputusan

Matriks keputusan adalah matriks yang berisis nilai setiap kriteria pada setiap alternatif. Jika A merupakan alternatif, dan $\mathrm{C}$ merupakan Kriteria yang di tetapkan dan jika X merupakan atribut dari kriteria, maka tabel yang digunakan untuk menjelaskan keputusan.

2. Matriks keputusan yang ternormalisasi

Normalisasi pada setiap atribut matriks keputusan dilakukan dengan cara membandingkan setiap atribut pada setiap alternatif dengan akar jumlah kuadrat setiap elemen pada kriteria yang sama semua alternatif. persamaan yang digunakan untuk melakukan normalisasi pada setiap atribut matriks.

3. Menghitung matriks keputusan yang ternormalisasi terbobot

Matriks keputusan normalisasi terbobot dilambangkan dengan huruf $\mathrm{Y}$, untuk mencari elemen matriks $\mathrm{Y}$ dilakukan dengan membagi elemen matriks keputusan ternormalisasi $(R)$ dengan elemen pada vector bobot preferensi (w). Matriks R akan diubah menjadi matriks Y dengan cara merubah satu persatu nilai atribut dari matriks R.

4. Menghitung matriks solusi ideal positif dan matriks solusi ideal negatif

Solusi ideal positif dan matriks solusi ideal negatif dapat ditentukan berdasarkan rating bobot ternormalisasi. Menghitung jarak antara nilai terbobot setiap alternatif terhadap solusi ideal positif dan solusi ideal negartif. jarak antara alternatif dengan solusi ideal positif.

5. Menghitung nilai preferensi untuk setiap alternatif.

Nilai preferensi merupakan nilai akhir yang menjadi patokan dalam menentukan peringkat pada semua alternatif yang ada. Hal tersebut berarti semua alternatif akan memiliki nilai preferensi. Nilai preferensi pada suatu alternatif merupakan hasil dari perbandingan setiap alternatif antara jarak terhadap solusi ideal positif dan jarak terhadap solusi ideal negatif.

\section{HASIL DAN PEMBAHASAN}

\subsection{Data Awal}

Data pada penelitian ini yang digunakan merupakan data mentah dari perusahaan yang berbentuk file excel dimana saat ini data karyawan yang sedang melakukan pengajuan untuk mendapatkan rumah dinas pada perusahaan Bridgestone berjumlah 53 orang dari 201 jumlah karyawan. Data dapat di lihat pada tabel 1.

Tabel 1. Data Karyawan Yang Sedang Melakukan PEngajuan Rumah Dinas

\begin{tabular}{clccc}
\hline No & Karyawan & Lama Masa Kerja & Status Perkawinan & Jumlah Anak \\
\hline 1 & Karyawan 1 & 16 & Menikah & 3 \\
2 & Karyawan 2 & 16 & Menikah & 3 \\
3 & Karyawan 3 & 22 & Menikah & 3 \\
4 & Karyawan 4 & 16 & Menikah & 3 \\
5 & Karyawan 5 & 22 & Menikah & 3 \\
6 & Karyawan 6 & 23 & Janda & 3 \\
7 & Karyawan 7 & 19 & Duda & 3 \\
8 & Karyawan 8 & 20 & Duda & 3 \\
9 & Karyawan 9 & 25 & Janda & 3 \\
10 & Karyawan 10 & 19 & Janda & 3 \\
11 & Karyawan 11 & Menikah & 2 \\
12 & Karyawan 12 & Menikah & 2 \\
13 & Karyawan 13 & 20 & Belum Menikah & 3 \\
\hline
\end{tabular}


JURNAL MEDIA INFORMATIKA BUDIDARMA

Volume 5, Nomor 2, April 2021, Page 695-704

ISSN 2614-5278 (media cetak), ISSN 2548-8368 (media online)

Available Online at https://ejurnal.stmik-budidarma.ac.id/index.php/mib DOI 10.30865/mib.v5i2.2976

\begin{tabular}{|c|c|c|c|c|}
\hline No & Karyawan & Lama Masa Kerja & Status Perkawinan & Jumlah Anak \\
\hline 14 & Karyawan 14 & 23 & Belum Menikah & 3 \\
\hline 15 & Karyawan 15 & 21 & Menikah & 1 \\
\hline 16 & Karyawan 16 & 21 & Menikah & 1 \\
\hline 17 & Karyawan 17 & 24 & Menikah & 1 \\
\hline 18 & Karyawan 18 & 10 & Menikah & 3 \\
\hline 19 & Karyawan 19 & 17 & Menikah & 3 \\
\hline 20 & Karyawan 20 & 12 & Duda & 3 \\
\hline 21 & Karyawan 21 & 15 & Janda & 3 \\
\hline 22 & Karyawan 22 & 12 & Janda & 3 \\
\hline 23 & Karyawan 23 & 14 & Duda & 3 \\
\hline 24 & Karyawan 24 & 21 & Janda & 2 \\
\hline 25 & Karyawan 25 & 23 & Janda & 2 \\
\hline 26 & Karyawan 26 & 18 & Janda & 2 \\
\hline 27 & Karyawan 27 & 11 & Menikah & 2 \\
\hline 28 & Karyawan 28 & 17 & Janda & 1 \\
\hline 29 & Karyawan 29 & 13 & Belum Menikah & 3 \\
\hline 30 & Karyawan 30 & 9 & Janda & 3 \\
\hline 31 & Karyawan 31 & 7 & Duda & 3 \\
\hline 32 & Karyawan 32 & 7 & Janda & 3 \\
\hline 33 & Karyawan 33 & 7 & Janda & 3 \\
\hline 34 & Karyawan 34 & 15 & Menikah & 1 \\
\hline 35 & Karyawan 35 & 16 & Belum Menikah & 2 \\
\hline 36 & Karyawan 36 & 9 & Menikah & 2 \\
\hline 37 & Karyawan 37 & 8 & Menikah & 2 \\
\hline 38 & Karyawan 38 & 5 & Menikah & 2 \\
\hline 39 & Karyawan 39 & 9 & Belum Menikah & 3 \\
\hline 40 & Karyawan 40 & 8 & Menikah & 1 \\
\hline 41 & Karyawan 41 & 14 & Janda & 2 \\
\hline 42 & Karyawan 42 & 5 & Menikah & 1 \\
\hline 43 & Karyawan 43 & 14 & Janda & 1 \\
\hline 44 & Karyawan 44 & 12 & Janda & 1 \\
\hline 45 & Karyawan 45 & 8 & Janda & 2 \\
\hline 46 & Karyawan 46 & 13 & Belum Menikah & 1 \\
\hline 47 & Karyawan 47 & 14 & Belum Menikah & 1 \\
\hline 48 & Karyawan 48 & 7 & Duda & 1 \\
\hline 49 & Karyawan 49 & 7 & Duda & 1 \\
\hline 50 & Karyawan 50 & 6 & Belum Menikah & 2 \\
\hline 51 & Karyawan 51 & 6 & Belum Menikah & 2 \\
\hline 52 & Karyawan 52 & 6 & Belum Menikah & 2 \\
\hline 53 & Karyawan 53 & 5 & Duda & 1 \\
\hline
\end{tabular}

\subsection{Data Kriteria}

Pada penelitian ini data kriteria adalah dating aturan yang di dapat pada perusahaan Bridgestone yang digunakan untuk memproses data pada penelitian ini dapat di lihat pada tabel 2.

Tabel 2. Data Kriteria

\begin{tabular}{cc}
\hline No & Kriteria \\
\hline 1 & Lama Masa Kerja \\
2 & Status Perkawinan \\
3 & Jumlah Anak \\
\hline
\end{tabular}

1. Lama Masa Kerja

Lama masa kerja nilai yang di dapat dari lamanya bekerja oleh seorang staff/karyawan pada perusahaan semakin lama karyawan berkeja maka semakin besar kemungkinan untuk mendapatkan fasilitas rumah dinas.

2. Status Perkawinan

Data pada status perkawinan nilai yang di tentukan dari status karyawan yang sudah menikah, janda/Duda, dan belum menikah, data ketegori pada status perkawinan.

3. Jumlah Anak

Data jumlah anak adalah data tanggungan dari seorang karyawan, dengan batas anak paling banyak adalah 3 orang anak 
JURNAL MEDIA INFORMATIKA BUDIDARMA

Volume 5, Nomor 2, April 2021, Page 695-704

ISSN 2614-5278 (media cetak), ISSN 2548-8368 (media online)

Available Online at https://ejurnal.stmik-budidarma.ac.id/index.php/mib DOI 10.30865/mib.v5i2.2976

\subsection{Data Sub Kriteria}

Data sub kriteri ini adalah hasil akhir yang akan di gunakan dalam analisa pada penelitian ini sub kriteria akan di tentukan layak dan tidak layaknya melalui rangking hasil analisa dari ke dua metode. sub kriteria dapat di lihat pada tabel 3 .

Tabel 3. Kategori Sub Kriteria

\begin{tabular}{clc}
\hline NO & \multicolumn{1}{c}{ Sub Kriteria } & Keterangan \\
\hline 1 & Sangat Layak & Nilai Tertinggi \\
2 & Layak & \\
3 & Cukup Layak & \\
4 & Tidak Layak & Nilai Terendah \\
\hline
\end{tabular}

\subsection{Hasil Analisa}

\subsubsection{Perhitungan Analytical Hierarchy Process (AHP)}

Pada tahap ini dilakukan perhitungan perbandingan antara satu kriteria dengan kriteria yang lainnya.

Tabel 4. Hasil Perhitungan Perbandingan Antara Kriteria

\begin{tabular}{cccc}
\hline KRITERIA & Lama Masa Kerja & Status Perkawinan & Jumlah Anak \\
\hline Lama Masa Kerja & 1 & 5 & 3 \\
Status Perkawinan & 0.2 & 1 & 0.2 \\
Jumlah Anak & 0.333 & 5 & 1 \\
TOTAL & 1.533 & 11 & 4.2 \\
\hline
\end{tabular}

Menguji konsistensi setiap matriks berpasangan dengan rumus masing-masing elemen matriks berpasangan dikalikan dengan nilai prioritas kriteria. Hasilnya masing-masing baris dijumlah, kemudian hasilnya dengan masing-masing nilai prioritas kriteria sebanyak $\lambda 1, \lambda 2, \lambda 3, \ldots, \lambda \mathrm{n}$. Menghitung nilai lamda maksimum dengan rumus: $\lambda \max =\Sigma \lambda / \mathrm{n}$. Menghitung nilai Indeks Konsistensi, dengan rumus: $C I=(\lambda \max -n) /(n-1)$. Menghitung Rasio Konsistensi, dengan rumus: $\mathrm{CR}=\mathrm{CI} / \mathrm{RI}$ Jika $\mathrm{CR}<0,1$, maka nilai perbandingan berpasangan pada matriks kriteria yang diberikan konsisten. Jika $\mathrm{CR} \geq 0,1$, maka nilai perbandingan berpasangan pada matriks kriteria yang diberikan tidak konsisten. Sehingga jika tidak konsisten, maka pengisian nilai-nilai pada matriks berpasangan pada unsur kriteria harus diulang. Sehingga mendapatkan hasil seperti tabel 5.

Tabel 5. Rasio Konsistensi

\begin{tabular}{cccc}
\hline KRITERIA & PRIORITAS & JUMLAH & HASIL \\
\hline Lama Masa Kejra & 0.607 & 1.965 & 2.572 \\
Status Perkawinan & 0.090 & 0.272 & 0.361 \\
Jumlah Anak & 0.303 & 0.954 & 1.257 \\
& TOTAL & & 4.191 \\
\hline
\end{tabular}

Rasio konsistensi dengan melihat index konsistensi. Konsistensi yang diharapkan pada penelitian ini adalah yang mendekati $100 \%$ agar menghasilkan keputusan yang mendekati layak atau tidak layaknya.

Tabel 6. Hasil Analisa AHP Terhadap Data

\begin{tabular}{lcccc}
\hline & Lama Masa Kerja & Status Perkawinan & Jumlah Anak & Hasil AHP \\
\hline Karyawan 50 & 22 & Menikah & 3 & 3 \\
Karyawan 53 & 22 & Menikah & 3 & 3 \\
Karyawan 31 & 16 & Menikah & 3 & 3 \\
Karyawan 49 & 16 & Menikah & 3 & 3 \\
Karyawan 52 & 16 & Menikah & 3 & 3 \\
Karyawan 24 & 25 & Janda & 3 & 2.499 \\
Karyawan 15 & 23 & Janda & 3 & 2.499 \\
Karyawan 20 & 20 & Duda & 3 & 2.499 \\
Karyawan 17 & 19 & Duda & 3 & 2.499 \\
Karyawan 28 & 19 & Janda & 3 & 2.499 \\
Karyawan 35 & 20 & Menikah & 2 & 2.419 \\
Karyawan 10 & 19 & Menikah & 2 & 2.419 \\
Karyawan 37 & 23 & Belum Menikah & 3 & 2.244 \\
Karyawan 16 & 16 & Belum Menikah & 3 & 2.244 \\
Karyawan 22 & 24 & Menikah & 1 & 2.218 \\
Karyawan 5 & 21 & Menikah & 1 & 2.218 \\
\hline
\end{tabular}


JURNAL MEDIA INFORMATIKA BUDIDARMA

Volume 5, Nomor 2, April 2021, Page 695-704

ISSN 2614-5278 (media cetak), ISSN 2548-8368 (media online)

Available Online at https://ejurnal.stmik-budidarma.ac.id/index.php/mib DOI 10.30865/mib.v5i2.2976

\begin{tabular}{|c|c|c|c|c|}
\hline & Lama Masa Kerja & Status Perkawinan & Jumlah Anak & Hasil AHP \\
\hline Karyawan 6 & 21 & Menikah & 1 & 2.218 \\
\hline Karyawan 23 & 10 & Menikah & 3 & 2.202 \\
\hline Karyawan 45 & 17 & Janda & 3 & 2 \\
\hline Karyawan 40 & 15 & Janda & 3 & 1.964 \\
\hline Karyawan 46 & 14 & Duda & 3 & 1.964 \\
\hline Karyawan 25 & 12 & Duda & 3 & 1.964 \\
\hline Karyawan 43 & 12 & Janda & 3 & 1.964 \\
\hline Karyawan 13 & 23 & Janda & 2 & 1.918 \\
\hline Karyawan 9 & 21 & Janda & 2 & 1.918 \\
\hline Karyawan 32 & 18 & Janda & 2 & 1.918 \\
\hline Karyawan 18 & 11 & Menikah & 2 & 1.884 \\
\hline Karyawan 36 & 17 & Janda & 1 & 1.717 \\
\hline Karyawan 7 & 13 & Belum Menikah & 3 & 1.709 \\
\hline Karyawan 4 & 9 & Janda & 3 & 1.701 \\
\hline Karyawan 26 & 7 & Duda & 3 & 1.701 \\
\hline Karyawan 30 & 7 & Janda & 3 & 1.701 \\
\hline Karyawan 34 & 7 & Janda & 3 & 1.701 \\
\hline Karyawan 39 & 15 & Menikah & 1 & 1.683 \\
\hline Karyawan 12 & 16 & Belum Menikah & 2 & 1.663 \\
\hline Karyawan 1 & 9 & Menikah & 2 & 1.621 \\
\hline Karyawan 27 & 8 & Menikah & 2 & 1.621 \\
\hline Karyawan 8 & 5 & Menikah & 2 & 1.545 \\
\hline Karyawan 3 & 9 & Belum Menikah & 3 & 1.446 \\
\hline Karyawan 42 & 8 & Menikah & 1 & 1.42 \\
\hline Karyawan 11 & 14 & Janda & 2 & 1.383 \\
\hline Karyawan 14 & 5 & Menikah & 1 & 1.344 \\
\hline Karyawan 2 & 14 & Janda & 1 & 1.182 \\
\hline Karyawan 19 & 12 & Janda & 1 & 1.182 \\
\hline Karyawan 21 & 8 & Janda & 2 & 1.12 \\
\hline Karyawan 44 & 14 & Belum Menikah & 1 & 0.927 \\
\hline Karyawan 33 & 13 & Belum Menikah & 1 & 0.927 \\
\hline Karyawan 48 & 7 & Duda & 1 & 0.919 \\
\hline Karyawan 51 & 7 & Duda & 1 & 0.919 \\
\hline Karyawan 29 & 6 & Belum Menikah & 2 & 0.865 \\
\hline Karyawan 41 & 6 & Belum Menikah & 2 & 0.865 \\
\hline
\end{tabular}

\subsubsection{Analisa Metode Technique for Order Preference by Similarity to Ideal Solution (TOPSIS)}

Untuk menghitung normalisasi maka di gunakan rumus persamaan sebagai berikut:

$$
r_{i j}=\frac{X_{i j}}{\sqrt{\sum_{i=1}^{m} X_{i j}^{2}}}
$$

Tabel 7. Hasil Anlisa Normaslisai Keriteria

\begin{tabular}{lccc}
\hline Normalisasi & Lama Masa Kerja & Status Perkawinan & Jumlah Anak \\
\hline Karyawan 1 & 0.061 & 0.196 & 0.117 \\
Karyawan 2 & 0.122 & 0.098 & 0.059 \\
Karyawan 3 & 0.061 & 0 & 0.176 \\
Karyawan 4 & 0.061 & 0.098 & 0.176 \\
Karyawan 5 & 0.184 & 0.196 & 0.059 \\
Karyawan 6 & 0.184 & 0.196 & 0.059 \\
Karyawan 7 & 0.122 & 0 & 0.176 \\
Karyawan 8 & 0 & 0.196 & 0.117 \\
Karyawan 9 & 0.184 & 0.098 & 0.117 \\
Karyawan 10 & 0.184 & 0.196 & 0.117 \\
Karyawan 11 & 0.122 & 0.098 & 0.117 \\
Karyawan 12 & 0.184 & 0.196 & 0.117 \\
Karyawan 13 & 0.184 & 0.098 & 0.117 \\
Karyawan 14 & 0 & 0.196 & 0.059 \\
Karyawan 15 & 0.184 & 0.098 & 0.176 \\
Karyawan 16 & 0.184 & 0 & 0.176 \\
\hline
\end{tabular}


JURNAL MEDIA INFORMATIKA BUDIDARMA

Volume 5, Nomor 2, April 2021, Page 695-704

ISSN 2614-5278 (media cetak), ISSN 2548-8368 (media online)

Available Online at https://ejurnal.stmik-budidarma.ac.id/index.php/mib DOI 10.30865/mib.v5i2.2976

\begin{tabular}{|c|c|c|c|}
\hline Normalisasi & Lama Masa Kerja & Status Perkawinan & Jumlah Anak \\
\hline Karyawan 17 & 0.184 & 0.098 & 0.176 \\
\hline Karyawan 18 & 0.122 & 0.196 & 0.117 \\
\hline Karyawan 19 & 0.122 & 0.098 & 0.059 \\
\hline Karyawan 20 & 0.184 & 0.098 & 0.176 \\
\hline Karyawan 21 & 0.061 & 0.098 & 0.117 \\
\hline Karyawan 22 & 0.184 & 0.196 & 0.059 \\
\hline Karyawan 23 & 0.061 & 0.196 & 0.176 \\
\hline Karyawan 24 & 0.184 & 0.098 & 0.176 \\
\hline Karyawan 25 & 0.122 & 0.098 & 0.176 \\
\hline Karyawan 26 & 0.061 & 0.098 & 0.176 \\
\hline Karyawan 27 & 0.061 & 0.196 & 0.117 \\
\hline Karyawan 28 & 0.184 & 0.098 & 0.176 \\
\hline Karyawan 29 & 0.061 & 0 & 0.117 \\
\hline Karyawan 30 & 0.061 & 0.098 & 0.176 \\
\hline Karyawan 31 & 0.184 & 0.196 & 0.176 \\
\hline Karyawan 32 & 0.184 & 0.098 & 0.117 \\
\hline Karyawan 33 & 0.122 & 0 & 0.059 \\
\hline Karyawan 34 & 0.061 & 0.098 & 0.176 \\
\hline Karyawan 35 & 0.184 & 0.196 & 0.117 \\
\hline Karyawan 36 & 0.184 & 0.098 & 0.059 \\
\hline Karyawan 37 & 0.184 & 0 & 0.176 \\
\hline Karyawan 38 & 0 & 0.098 & 0.059 \\
\hline Karyawan 39 & 0.122 & 0.196 & 0.059 \\
\hline Karyawan 40 & 0.122 & 0.098 & 0.176 \\
\hline Karyawan 41 & 0.061 & 0 & 0.117 \\
\hline Karyawan 42 & 0.061 & 0.196 & 0.059 \\
\hline Karyawan 43 & 0.061 & 0.098 & 0.176 \\
\hline Karyawan 44 & 0.122 & 0 & 0.059 \\
\hline Karyawan 45 & 0.184 & 0.196 & 0.176 \\
\hline Karyawan 46 & 0.122 & 0.098 & 0.176 \\
\hline Karyawan 47 & 0.061 & 0 & 0.117 \\
\hline Karyawan 48 & 0.061 & 0.098 & 0.059 \\
\hline Karyawan 49 & 0.184 & 0.196 & 0.176 \\
\hline Karyawan 50 & 0.184 & 0.196 & 0.176 \\
\hline Karyawan 51 & 0.061 & 0.098 & 0.059 \\
\hline Karyawan 52 & 0.184 & 0.196 & 0.176 \\
\hline Karyawan 53 & 0.184 & 0.196 & 0.176 \\
\hline
\end{tabular}

Untuk menghitung jarak antara nilai terbobot setiap alternatif terhadap solusi ideal negatif Pada tahap akhir dilakukan perhitungan nilai preferensi untuk setiap alternatif dengan menggunakan rumus persamaan sebagai berikut;

$$
V_{i}=\frac{D_{i}^{-}}{D_{i}^{-}+D_{i}^{+}}
$$

Tabel 8. Hasil Analisa TOPSIS

\begin{tabular}{lcccc}
\hline & Lama Masa Kejra & Status Perkawinan & Jumlah Anak & Hasil TOPSIS \\
\hline Karyawan 50 & 22 & Menikah & 3 & 1 \\
Karyawan 53 & 22 & Menikah & 3 & 1 \\
Karyawan 31 & 16 & Menikah & 3 & 1 \\
Karyawan 49 & 16 & Menikah & 3 & 1 \\
Karyawan 52 & 16 & Menikah & 3 & 1 \\
Karyawan 24 & 25 & Janda & 3 & 0.771 \\
Karyawan 15 & 23 & Janda & 3 & 0.771 \\
Karyawan 20 & 20 & Duda & 3 & 0.771 \\
Karyawan 17 & 19 & Duda & 3 & 0.771 \\
Karyawan 28 & 19 & Janda & 3 & 0.771 \\
Karyawan 35 & 20 & Menikah & 2 & 0.903 \\
Karyawan 10 & 19 & Menikah & 2 & 0.903 \\
Karyawan 37 & 23 & Belum Menikah & 3 & 0.617 \\
Karyawan 16 & 16 & Belum Menikah & 3 & 0.617 \\
\hline
\end{tabular}


JURNAL MEDIA INFORMATIKA BUDIDARMA

Volume 5, Nomor 2, April 2021, Page 695-704

ISSN 2614-5278 (media cetak), ISSN 2548-8368 (media online)

Available Online at https://ejurnal.stmik-budidarma.ac.id/index.php/mib DOI 10.30865/mib.v5i2.2976

\begin{tabular}{|c|c|c|c|c|}
\hline & Lama Masa Kejra & Status Perkawinan & Jumlah Anak & Hasil TOPSIS \\
\hline Karyawan 22 & 24 & Menikah & 1 & 0.823 \\
\hline Karyawan 5 & 21 & Menikah & 1 & 0.823 \\
\hline Karyawan 6 & 21 & Menikah & 1 & 0.823 \\
\hline Karyawan 23 & 10 & Menikah & 3 & 0.535 \\
\hline Karyawan 45 & 17 & Janda & 3 & 1 \\
\hline Karyawan 40 & 15 & Janda & 3 & 0.629 \\
\hline Karyawan 46 & 14 & Duda & 3 & 0.629 \\
\hline Karyawan 25 & 12 & Duda & 3 & 0.629 \\
\hline Karyawan 43 & 12 & Janda & 3 & 0.417 \\
\hline Karyawan 13 & 23 & Janda & 2 & 0.754 \\
\hline Karyawan 9 & 21 & Janda & 2 & 0.754 \\
\hline Karyawan 32 & 18 & Janda & 2 & 0.754 \\
\hline Karyawan 18 & 11 & Menikah & 2 & 0.723 \\
\hline Karyawan 36 & 17 & Janda & 1 & 0.719 \\
\hline Karyawan 7 & 13 & Belum Menikah & 3 & 0.497 \\
\hline Karyawan 4 & 9 & Janda & 3 & 0.417 \\
\hline Karyawan 26 & 7 & Duda & 3 & 0.417 \\
\hline Karyawan 30 & 7 & Janda & 3 & 0.417 \\
\hline Karyawan 34 & 7 & Janda & 3 & 0.417 \\
\hline Karyawan 39 & 15 & Menikah & 1 & 0.688 \\
\hline Karyawan 12 & 16 & Belum Menikah & 2 & 0.903 \\
\hline Karyawan 1 & 9 & Menikah & 2 & 0.519 \\
\hline Karyawan 27 & 8 & Menikah & 2 & 0.519 \\
\hline Karyawan 8 & 5 & Menikah & 2 & 0.393 \\
\hline Karyawan 3 & 9 & Belum Menikah & 3 & 0.312 \\
\hline Karyawan 42 & 8 & Menikah & 1 & 0.503 \\
\hline Karyawan 11 & 14 & Janda & 2 & 0.61 \\
\hline Karyawan 14 & 5 & Menikah & 1 & 0.383 \\
\hline Karyawan 2 & 14 & Janda & 1 & 0.583 \\
\hline Karyawan 19 & 12 & Janda & 1 & 0.583 \\
\hline Karyawan 21 & 8 & Janda & 2 & 0.39 \\
\hline Karyawan 44 & 14 & Belum Menikah & 1 & 0.465 \\
\hline Karyawan 33 & 13 & Belum Menikah & 1 & 0.465 \\
\hline Karyawan 48 & 7 & Duda & 1 & 0.371 \\
\hline Karyawan 51 & 7 & Duda & 1 & 0.371 \\
\hline Karyawan 29 & 6 & Belum Menikah & 2 & 0.277 \\
\hline Karyawan 41 & 6 & Belum Menikah & 2 & 0.277 \\
\hline Karyawan 47 & 6 & Belum Menikah & 2 & 0.277 \\
\hline Karyawan 38 & 5 & Duda & 1 & 0.229 \\
\hline
\end{tabular}

\subsection{Hasil Evaluasi Data Terhadap Kedua Metode}

Dimana hasil penilaiannya dari masing-masing kriteria berdasarkan alternatif prioritas yang sudah ditentukan. Sehingga hasil perhitungan dari kedua metode dapat diketahui siapa yang layak untuk mendapatkan fasilitas rumah dinas berdasarkan rangking yang diperoleh dengan menggunakan metode AHP \& TOPSIS. Hasil perbandingan antara ke dua metode yaitu AHP dan TOPSIS dapat di lihat pada tabel 9.

Tabel 9. Hasil Evaluasi Antara AHP \& TOPSIS

\begin{tabular}{|c|c|c|c|c|c|c|c|}
\hline & $\begin{array}{c}\text { Lama Masa } \\
\text { Kerja }\end{array}$ & $\begin{array}{c}\text { Status } \\
\text { Perkawinan }\end{array}$ & $\begin{array}{c}\text { Jumlah } \\
\text { Anak }\end{array}$ & $\begin{array}{l}\text { Hasil } \\
\text { AHP }\end{array}$ & $\begin{array}{c}\text { Hasil } \\
\text { TOPSIS }\end{array}$ & Rangking & $\begin{array}{c}\text { Status } \\
\text { Kelayakan }\end{array}$ \\
\hline Karyawan 50 & 22 & Menikah & 3 & 3 & 1 & 4 & Sangat Layak \\
\hline Karyawan 53 & 22 & Menikah & 3 & 3 & 1 & 4 & Sangat Layak \\
\hline Karyawan 31 & 16 & Menikah & 3 & 3 & 1 & 4 & Sangat Layak \\
\hline Karyawan 49 & 16 & Menikah & 3 & 3 & 1 & 4 & Sangat Layak \\
\hline Karyawan 52 & 16 & Menikah & 3 & 3 & 1 & 4 & Sangat Layak \\
\hline Karyawan 24 & 25 & Janda & 3 & 2.499 & 0.771 & 3 & Layak \\
\hline Karyawan 15 & 23 & Janda & 3 & 2.499 & 0.771 & 3 & Layak \\
\hline Karyawan 20 & 20 & Duda & 3 & 2.499 & 0.771 & 3 & Layak \\
\hline Karyawan 17 & 19 & Duda & 3 & 2.499 & 0.771 & 3 & Layak \\
\hline Karyawan 28 & 19 & Janda & 3 & 2.499 & 0.771 & 3 & Layak \\
\hline Karyawan 35 & 20 & Menikah & 2 & 2.419 & 0.903 & 3 & Layak \\
\hline
\end{tabular}


JURNAL MEDIA INFORMATIKA BUDIDARMA

Volume 5, Nomor 2, April 2021, Page 695-704

ISSN 2614-5278 (media cetak), ISSN 2548-8368 (media online)

Available Online at https://ejurnal.stmik-budidarma.ac.id/index.php/mib DOI 10.30865/mib.v5i2.2976

\begin{tabular}{|c|c|c|c|c|c|c|c|}
\hline & $\begin{array}{c}\text { Lama Masa } \\
\text { Kerja }\end{array}$ & $\begin{array}{c}\text { Status } \\
\text { Perkawinan }\end{array}$ & $\begin{array}{l}\text { Jumlah } \\
\text { Anak }\end{array}$ & $\begin{array}{l}\text { Hasil } \\
\text { AHP }\end{array}$ & $\begin{array}{c}\text { Hasil } \\
\text { TOPSIS }\end{array}$ & Rangking & $\begin{array}{c}\text { Status } \\
\text { Kelayakan }\end{array}$ \\
\hline Karyawan 10 & 19 & Menikah & 2 & 2.419 & 0.903 & 3 & Layak \\
\hline Karyawan 37 & 23 & Belum Menikah & 3 & 2.244 & 0.617 & 3 & Cukup Layak \\
\hline Karyawan 16 & 16 & Belum Menikah & 3 & 2.244 & 0.617 & 3 & Cukup Layak \\
\hline Karyawan 22 & 24 & Menikah & 1 & 2.218 & 0.823 & 3 & Layak \\
\hline Karyawan 5 & 21 & Menikah & 1 & 2.218 & 0.823 & 3 & Layak \\
\hline Karyawan 6 & 21 & Menikah & 1 & 2.218 & 0.823 & 3 & Layak \\
\hline Karyawan 23 & 10 & Menikah & 3 & 2.202 & 0.535 & 3 & Cukup Layak \\
\hline Karyawan 45 & 17 & Janda & 3 & 2 & 1 & 3 & Layak \\
\hline Karyawan 40 & 15 & Janda & 3 & 1.964 & 0.629 & 3 & Cukup Layak \\
\hline Karyawan 46 & 14 & Duda & 3 & 1.964 & 0.629 & 3 & Cukup Layak \\
\hline Karyawan 25 & 12 & Duda & 3 & 1.964 & 0.629 & 3 & Cukup Layak \\
\hline Karyawan 43 & 12 & Janda & 3 & 1.964 & 0.417 & 2 & Cukup Layak \\
\hline Karyawan 13 & 23 & Janda & 2 & 1.918 & 0.754 & 3 & Cukup Layak \\
\hline Karyawan 9 & 21 & Janda & 2 & 1.918 & 0.754 & 3 & Cukup Layak \\
\hline Karyawan 32 & 18 & Janda & 2 & 1.918 & 0.754 & 3 & Cukup Layak \\
\hline Karyawan 18 & 11 & Menikah & 2 & 1.884 & 0.723 & 3 & Cukup Layak \\
\hline Karyawan 36 & 17 & Janda & 1 & 1.717 & 0.719 & 2 & Cukup Layak \\
\hline Karyawan 7 & 13 & Belum Menikah & 3 & 1.709 & 0.497 & 2 & Cukup Layak \\
\hline Karyawan 4 & 9 & Janda & 3 & 1.701 & 0.417 & 2 & Cukup Layak \\
\hline Karyawan 26 & 7 & Duda & 3 & 1.701 & 0.417 & 2 & Cukup Layak \\
\hline Karyawan 30 & 7 & Janda & 3 & 1.701 & 0.417 & 2 & Cukup Layak \\
\hline Karyawan 34 & 7 & Janda & 3 & 1.701 & 0.417 & 2 & Cukup Layak \\
\hline Karyawan 39 & 15 & Menikah & 1 & 1.683 & 0.688 & 2 & Cukup Layak \\
\hline Karyawan 12 & 16 & Belum Menikah & 2 & 1.663 & 0.903 & 3 & Cukup Layak \\
\hline Karyawan 1 & 9 & Menikah & 2 & 1.621 & 0.519 & 2 & Cukup Layak \\
\hline Karyawan 27 & 8 & Menikah & 2 & 1.621 & 0.519 & 2 & Cukup Layak \\
\hline Karyawan 8 & 5 & Menikah & 2 & 1.545 & 0.393 & 2 & Tidak Layak \\
\hline Karyawan 3 & 9 & Belum Menikah & 3 & 1.446 & 0.312 & 2 & Tidak Layak \\
\hline Karyawan 42 & 8 & Menikah & 1 & 1.42 & 0.503 & 2 & Tidak Layak \\
\hline Karyawan 11 & 14 & Janda & 2 & 1.383 & 0.61 & 2 & Tidak Layak \\
\hline Karyawan 14 & 5 & Menikah & 1 & 1.344 & 0.383 & 2 & Tidak Layak \\
\hline Karyawan 2 & 14 & Janda & 1 & 1.182 & 0.583 & 2 & Tidak Layak \\
\hline Karyawan 19 & 12 & Janda & 1 & 1.182 & 0.583 & 2 & Tidak Layak \\
\hline Karyawan 21 & 8 & Janda & 2 & 1.12 & 0.39 & 2 & Tidak Layak \\
\hline Karyawan 44 & 14 & Belum Menikah & 1 & 0.927 & 0.465 & 1 & Tidak Layak \\
\hline Karyawan 33 & 13 & Belum Menikah & 1 & 0.927 & 0.465 & 1 & Tidak Layak \\
\hline Karyawan 48 & 7 & Duda & 1 & 0.919 & 0.371 & 1 & Tidak Layak \\
\hline Karyawan 51 & 7 & Duda & 1 & 0.919 & 0.371 & 1 & Tidak Layak \\
\hline Karyawan 29 & 6 & Belum Menikah & 2 & 0.865 & 0.277 & 1 & Tidak Layak \\
\hline Karyawan 41 & 6 & Belum Menikah & 2 & 0.865 & 0.277 & 1 & Tidak Layak \\
\hline Karyawan 47 & 6 & Belum Menikah & 2 & 0.865 & 0.277 & 1 & Tidak Layak \\
\hline Karyawan 38 & 5 & Duda & 1 & 0.843 & 0.229 & 1 & Tidak Layak \\
\hline
\end{tabular}

Pada analisa yang di lakukan terhadap penelitian ini maka dapat di simpulkan bahwa metode (Analytical Hierarchy Process) AHP jauh lebih akurat di bandingkan dengan metode Technique for Order Preference by Similarity to Ideal Solution (TOPSIS).di karenakan Analisa yang di hasilkan (Analytical Hierarchy Process) AHP menghitung bobot semua kriteria sehingga dapat menghasilkan perbandingan yang akurat dimana hasil akhirnya adalah 5 orang yaitu karyawan $(31,49,50,51,53)$ yang layak mendapatkan rumah dinas. Sedangkan pada analisa metode Technique for Order Preference by Similarity to Ideal Solution (TOPSIS) data Analisa yang di haslikan hanya sebatas 1-0 sehingga hanya menghasilkan rangking nilai tertinggi dan terendah dari setiap karyawan tanpa menghitung setiap kriteria. Dari hasil metode Technique for Order Preference by Similarity to Ideal Solution (TOPSIS) karyawan yang layak adalah 6 orang yaitu karyawan $(31,45,49,50,52,53)$.

\section{KESIMPULAN}

Hasil evaluasi hasil dari hasil analisa metode AHP dan TOPSIS terhadap data maka untuk menentukan rumah dinas yang dilakukan oleh perusahaan Bridgestone jauh lebih efektif dan transparan. Sehingga tidak merugikan pihak karyawan. Dari kedua metode AHP dan TOPSIS yang paling efektif adalah dengan menggunakan metode AHP, dimana AHP menghasilkan karyawan yang layak mendapatkan rumah dinas adalah 5 orang, dimna ke lima 
karyawan tersebut memiliki data proritas pertama dalam kriteria. Sedangkan pada metode TOPSIS menghasilkan 6 orang untuk mendapatkan kelayakan rumah dinas, metode ini kurang akurat dikarenakan hanya melakukan perengkingen sehingga dari evaluasi hasil Analisa diatas terdapat 1 orang karyawan yaoti karyawan 45 masuk kategori sangat layak jika dilihat data aslinya karyawan 45 tersebut memiliki proritas di bawah kriteria utama sehingga menimbulkan data yang kurnag akurat dan Sebaiknya untuk pengembangan perusahaan, harus membuat system yang menerapkan metode AHP dan TOPSIS dalam bentuk aplikasi agar memberikan transparan terhadap karyawan.

\section{UCAPAN TERIMAKASIH}

Terima kasih disampaikan kepada pihak perusahaan Bridgestone yang telah mendukung terlaksananya uji coba pada penelitian ini dan memberikan data untuk di lakukan studi analisa terhadap permasalahan yang ada.

\section{REFERENCES}

[1] Fatkhurrochman and D. Astuti, "Analisis Perbandingan Metode Topis Dan Saw Dalam Penentuan Penerima Bantuan Pengembangan Rumah Masyarakat Kurang Mampu," Semnasteknomedia Online, vol. 6, no. 1, pp. 2-8-67, 2018, [Online]. Available: https://ojs.amikom.ac.id/index.php/semnasteknomedia/article/view/1980.

[2] H. Nalatissifa and Y. Ramdhani, "Sistem Penunjang Keputusan Menggunakan Metode TOPSIS Untuk Menentukan Kelayakan Bantuan Rumah Tidak Layak Huni (RTLH)," MATRIK J. Manajemen, Tek. Inform. dan Rekayasa Komput., vol. 19, no. 2, pp. 246-256, 2020, doi: 10.30812/matrik.v19i2.638.

[3] E. J. G. Harianja and G. Lumbantoruan, "Penerapan Metode TOPSIS dalam Menentukan Penerima Bantuan Bedah Rumah Pada Dinas Perumahan Dan Kawasan Permukiman Kabupaten Deli Serdang,” J. Times, vol. 8, no. 1, pp. 29-38, 2019.

[4] M. R. Syahputra, “Aplikasi Fuzzy-TOPSIS Dalam Melakukan Seleksi Pemilihan Perumahan,” J. Mantik Penusa, vol. 15, no. Fakultas Manajemen dan Informatika Pelita Nusantara, pp. 123-128, 2014, [Online]. Available: file:///e:/Users/S u s e n o/Downloads/245-Article Text-584-1-10-20171028.pdf.

[5] Indriani; Dita Novitasari, "Penerapan Metode TOPSIS Untuk Menentukan Prioritas Kondisi Rumah," Acit, vol. 67, no. 6, pp. 14-21, 2007.

[6] Adianto, T. R., Arifin, Z., Khairina, D. M., Mahakam, G., \& Palm, G. (2017). Sistem Pendukung Keputusan Pemilihan Rumah Tinggal Di Perumahan Menggunakan Metode Simple Additive Weighting (Saw) (Studi Kasus: Kota Samarinda). Prosiding Seminar Ilmu Komputer dan Teknologi Informasi, 2(1), 197-201.

[7] Astuti, Y., Suyanto, M., \& Kusrini. (2012). AHP Untuk Pemodelan SPK Pemilihan Sekolah Tinggi Komputer. Jurnal Teknologi Informasi, 7(20), 81-90.

[8] Azmi, M. (2018). Sistem Pendukung Keputusan Untuk Memilih Usaha Waralaba Makanan Menggunakan Metode TOPSIS. Jurnal Elektron, 5(2), 61-68. https://doi.org/10.1016/j.cden.2017.05.001

[9] Badriyah, T., \& Rahmawati, R. (2006). Alat Bantu Klasifikasi Dengan Pohon Keputusan Untuk Sistem Pendukung Keputusan. Seminar Nasional Aplikasi Teknologi Informasi 2006 (SNATI 2006), 2006(Snati), 1-4.

[10] Chamid, A. A. (2016). Penerapan Metode TOPSIS Untuk Menentukan Prioritas Kondisi Rumah. Simetris : Jurnal Teknik Mesin, Elektro dan Ilmu Komputer, 7(2), 537. https://doi.org/10.24176/simet.v7i2.765

[11] Darmanto, E., Latifah, N., \& Susanti, N. (2014). Penerapan Metode Ahp (Analythic Hierarchy Process) Untuk Menentukan Kualitas Gula Tumbu. Simetris: Jurnal Teknik Mesin, Elektro dan Ilmu Komputer, 5(1), 75. https://doi.org/10.24176/simet.v5i1.139

[12] Faesal, A., Fauziati, S., \& Soesanti, I. (2017). Implementasi Metode AHP dan TOPSIS untuk menentukan Mutu Dosen. $7-13$.

[13] Fitriana, A. N., Harliana, H., \& Handaru, H. (2015). Sistem Pendukung Keputusan Untuk Menentukan Prestasi Akademik Siswa dengan Metode TOPSIS. Creative Information Technology Journal, 2(2), 153. https://doi.org/10.24076/citec.2015v2i2.45

[14] Mu'asyaroh, F. L., \& Mahmudy, W. F. (2016). Implementasi Algoritma Genetika Dalam Optimasi Model AHP. Jurnal Teknologi Informasi dan Ilmu Komputer, 3(4), 226-237.

[15] Muzakkir, I. (2017). Penerapan Metode TOPSIS Untuk Sistem Pendukung Keputusan Penentuan Keluarga Miskin Pada Desa Panca Karsa Ii. ILKOM Jurnal Ilmiah, 9(3), 274-281. https://doi.org/10.33096/ilkom.v9i3.156.274-281

[16] Rais, M. S. (2016). Sistem Pendukung Keputusan Untuk Pemilihan Lokasi Perumahan Menggunakan Analytical Hierarchy Process (AHP). Riau Journal Of Computer Science, 2(2), 59-72.

[17] Siregar, J. (2017). Sistem Pendukung Keputusan Pemberian Kpr (Kredit Pemilikan Rumah) Untuk Nasabah Pemohon Menggunakan Metode TOPSIS ( Studi Kasus Pt . Bank. Juli, 335-342.

[18] Tsabit Rahman dkk. (2017). Analisis Model Pengambil Keputusan AHP dan TOPSIS Untuk memilih Software Berbasis Open Source Digital Library pada Universitas Janabadra. Seminar Nasional Inovasi Teknologi UN PGRI Kediri, 22 Februari 2017, 1(Februari), 441-450. 